\title{
Interaction of Cultures as Factor of Consolidation of Ethnicity in Multi-lingual Space: In Example of the Republic of Tatarstan
}

\author{
Yanina O. Biketova* \\ Alsu F. Valeyeva \\ Albina K. Gizatullina
}

Kazan Federal University, Russian Federation; *Corresponding Email: b-yanina@mail.ru

\section{Doi:10.5901/mjss.2015.v6n6s7p46}

\begin{abstract}
In the light of inter-disciplinary approach, a number of aspects have been considered on the process of interaction of national cultures as a factor of consolidation of ethnic groups in a multi-lingual space. On the basis of the available in linguistic, sociolinguistic, sociological and cultural studies of theoretical works and methodological ideas, analysis has been made of empiric data of the Republic of Tatarstan. The most significant results of that analysis are presented as accessions and conclusions implicitly containing recommendations on optimization of inter-cultural communications with the purpose of improving the effectiveness of their influence on the unification and cooperation of peoples of the multi-lingual Tatarstan community.
\end{abstract}

Keywords: culture, inter-cultural communication, ethnos, consolidation of ethnic groups, multi-lingual space, linguistic behavior

\section{Introduction}

The ethno-cultural life of the Republic of Tatarstan is noted for the richness and variety of customs and traditions of the numerous peoples living in this multi-ethnical region. According to the results of the census of 2010 in the Republic of Tatarstan, out of 3.78 million people $53,2 \%$ are Tatars and $39,7 \%$ are Russians. Of the peoples of the Volga Region, Chuvashes, Udmurts, Mordovians, Mari and Bashkirs inhabit the territory of Tatarstan; the total of those peoples is 5.6\% of the population of the Republic.

In the context of modernization characteristic to multi-ethnic regional community in the multi-lingual space of the Republic of Tatarstan the preservation of tolerant relations between the peoples acquires a special significance. Consolidation of ethnic groups serves not only as a condition of inter-ethnic concord and peace, but also as a factor of enrichment and development of the cultures and languages of all the peoples living on the territory of the Republic. The cultural progress of the peoples and interaction of national cultures is the guarantee of the consolidation of ethnic groups into a unified multinational and multi-lingual community, whose developing social potential is great. The thickening and differentiation of social structure according to Durkheim (1893) signifies the achieved social progress and serves as a condition of further evolution of the socium to the state of organic solidarity.

Under modernization, similarly to Schtompka (1996) we mean a prolonged, complex and contradictive historical process of modernization and analytical construction of modern society, presenting a complex, multi-dimensioned change of the main spheres of social life. The interaction of cultures regarded as a factor of ethnic consolidation in the multilingual society vividly reflects the modernization as a constantly changing reality.

The main purpose of the present article is to trace some important aspects of cultural cooperation of ethnic groups as a factor of consolidation of peoples in a multilingual field, to assess them empirically and suggest a theoretical explanation of the already formed in Tatarstan model of intercultural interactions through the prism of their influence on the consolidation of regional ethnical communities. The theoretical explanation of empiric facts, the nature and peculiarities of interconnection of variables presupposes the support of the reliable time-proved, heuristically valuable notional apparatus, especially if the explanation of notions is varied. It is impossible to neglect the notion of culture, which is vast and polysemic. 


\section{Literature Review on the Problem}

The linguistic and sociological character of the article obliges to refer in the first place to lexical editions. Thus, the French explanatory dictionary Le Petit Larousse (1995) defines culture as a multitude of intellectual religious social structures and artistic actions, which define groups or societies in reference to one another.

The analyzed problem of interconnection of inter-cultural communications and consolidation of ethnic groups in a multi-lingual space is based on the definition of culture by $\mathrm{G}$. Hofstede, who has suggested on the basis of the sociological research a multitude of factors, defining the cultural characteristics of different peoples of the world. According to the Dutch sociologist, culture may be defined as "collective programming of intellect, which differentiates the members of one group or category of people from the people of other groups or categories" (Hofstede, 1990, p.231).

Explicating the notion of culture for the purpose of a deeper and more exact understanding of the essence of the phenomenon of interaction of cultures we are concentrating on the functional aspects of culture. Above all, culture encourages the formation of a personality, in which phenomenon it shows its humanitarian essence. The world is revealed through culture and self-realization. Regarding the regional peculiarity of cultural interactions, we point out that the Republic of Tatarstan is a multi-faced and multi-national structure, and it includes a whole conglomerate of subcultures, which are in a state of constant historical development, interacting among themselves and filling one another both morally and spiritually. Each people, each ethnos of the Republic has its own history, its national customs and traditions, different professional, social, demographical and ethnical components. During the ethnical contacts a process of inter-penetration takes place, a process of enrichment and even merging of the spiritual interests of the population. In the process of cooperation and interaction of languages and cultures, exchange of historical and cultural values, a new cultural conscience is formed.

Studying the features of cultural interactions in a multi-ethnic region, the researchers operate with the notions "multi-culturalism" and "multi-linguism", as a language is a sort of kernel, and at the same time a means of verbal expression of contents, nature and peculiarities of culture. These notions have no definitions given to them once and for all. With the development of ethno-cultural and lingual interactions, "multi-culturalism" and "multi-linguism", they are subjected to scientific discussions in the direction of better correspondence to the nature of phenomena, for the designation, description and explanation of which they were introduced for usage in science.

Referring to the problem of the interaction of the cultures of the peoples living in a multi-ethnic region in one multilingual space, it is also necessary to have an adequate idea of such notions as "cultural space", "cultural traditions", "cultural background", "cultural heritance" and "mentality".

Zamaletdinov and Sibgayeva (2013) analyzed all the above-mentioned notions presenting rather capacious, clear and distinct definitions. The use of the recited notions allows with sufficient fullness and exactitude to reflect the picture of the interactions of cultures in a polyethnic community, and also to diagnose the scale, degree and deepness of the interpenetration of cultures.

The theory of inter-cultural interactions differentiates them into four main types: assimilation, acculturation, cooperation and ethno-cultural isolationism. All those processes took place in the former Soviet Union, and they are taking place in today's Russia. Thus, assimilation is usually understood as the process of changing of ethnical identity and self-awareness of the people. The analysis has been given of inter-ethnic and inter-cultural communications that took place in the Soviet Union. But there were cultures, the objectified forms of which lost representativeness in spite of the preservation of ethnical consciousness. In particular, it concerns the cultures of Komi, Karels and some other peoples (Kozhanov, 2009).

Acculturation took place in the process of interaction of the Russian culture with the cultures of the mentioned Komi and Karels, and also to some extent with the cultures of Udmurts, Mordovians, Yakuts and a number of other peoples of Russia.

Rather a rare phenomenon in the Soviet years was the cooperation of national cultures, when the Russians living on the territory of national republics adopted the culture of the «title» peoples of those republics. More often, it concerned the people who had lived there for a long time. For example, it was the Russians who had lived long enough on the territory of Yakutia and in the Caucasus. For ideological reasons it was considered that cultural cooperation also took place in Estonia, Latvia and Lithuania.

\section{Objectives, Methodology and Research Design}

Methodological foundations of the work are based on the inter-disciplinary approach often used when investigating intercultural communications, particularly the formation of inter-cultural competence. The article suggests the use of complex 
scientific methodology, including systems approach, structural-functional, activity and a number of other widely used in modern sociology approaches. Vasilyeva (2013), grounding on the initial principles and reasons of inter-disciplinary approach, considers the problems of the interaction of linguistics, didactics and psychology in the formation of speech, linguistic and cultural sides of communicative competence. The realized inter-disciplinary approach mentioned by the author allows receiving a full and detailed idea of the process of inter-penetration of cultures of the peoples living in multiethnic regions, which takes place thanks to the active introduction of speech, linguistic and socio-cultural patterns of behavior into the modus vivendi of their representatives.

Developing the methodological principles evolved in the works of Vasilyeva (2013), Ostroumov and Ostroumova (2013, p.149) define the inter-cultural competence as a "synthesis of integrated skills and capabilities allowing to understand and imagine the peculiarities of alien culture in its different appearances with the purpose of providing of effective communication and adequate behavior in the context of inter-cultural dialogue". The given definition is rather capacious and consistently characterizes the inter-cultural competence, toning in communication in life activities of the peoples living for centuries on one common territory.

The above-mentioned authors pay attention to the objective needs of the modern stage of the development of society in the formation of multi-cultural linguistic personality possessing a high level of other-language communicative competence. We fully support the opinion of the researchers about the importance of such a quality of a linguistic personality as an ability and readiness for autonomous and supraliminal study of an alien language and another culture on the basis of introduction into the educational process of creative teaching aimed at the development of creative abilities and formation of a creative personality and search of real mechanisms to provide creative education. Such ideas also find support among philosophers. Epstein (1996) states that in order to survive and prosper in the $21^{\text {st }}$ century, the humanities must shift their focus from descriptive scholarship to creative thinking capable of producing new intellectual movements, spiritual, practices and socio-cultural institutions. The readiness and capability for autonomous and supraliminal study of a people's language and culture, formed on the basis of creative teaching, must be assessed as a most important condition of multilateral multicultural development of not only the most numerous ethnic groups of the Republic - Tatars and Russians, but also the representatives of all the other ethnic communities living in the Republic of Tatarstan.

The inter-disciplinary approach used in the article naturally pre-supposes the use of various research apparatus. The interaction of cultures in the light of the influence of the given interaction on the consolidation of ethnic groups in the multilingual space of a multi-ethnic region is considered from the point of view of the system method, structural-functional analysis, theory of social activity, ethnographical method, and also the methods of socio-linguistics and applied sociology.

The description of inter-cultural relations suggested in the article, of their nature and peculiarities is given proceeding from the data of official statistics with references to the comments on the ethno-cultural situation formed in the Republic, that has been presented by officials and specialists in the field of ethno-cultural interactions.

The researchers of the problem also give attention to the activities of the Assembly of the Peoples of Tatarstan, established in 2007 at the ninth Conference of the Association of National-Cultural unions of the Republic of Tatarstan (ANCU). It is a coordinating organ that includes all the national public organizations, representatives of communities, and also natural persons occupying responsible posts in state or public structures of the Republic. The Assembly is headed by Chairman of the State Council of RT Farid Mukhametshin. The statement characterizing him as a statesman and citizen states that in the foundation of multinational Russia there is understanding, concord and friendship despite the differences in languages, customs and traditions of peoples. We are all living in one common home, and we must treat it as a great wealth (Vasilyeva, 2013).

With the purpose of tracing the social interaction of national cultures as a factor of consolidation of ethnic groups in a multilingual space of the Republic of Tatarstan, a number of sociological investigations have been made during the last decade (2003-2013). The results of the following investigations allow us to trace to some extent the consolidating role of the interaction of national cultures in a multi-ethnic region (e.g. see Valeyeva (2004), Berezina (2011), Gabdrakhmanova (2013), Gilmanov and Mavlyautdinov (2010), Davletshina (2012), Iskhakova (2001), Lipatova (2012), Makarova (2012) and a number of others).

The empiric basis of investigation includes the results of a concrete sociological research $(n=900)$, held in January - February 2010 on the territory of the Republic of Tatarstan under the guidance of A.F. Valeyeva (Berezina, 2010). The aim was to reveal the attitude of the residents of Tatarstan to the linguistic behavior as an important conductor of interaction of cultures in the multilingual society. One of the main tasks of the research was to determine the interaction of cultures as a consolidating factor ensuring a mutually enreaching coexistence of a great multitude of ethnoses inhabiting the Republic of Tatarstan, actually 173 nationalities, among them at least 35 have their own diaspora (Gracheva, 2015). The selection was formed according to the quota-nest principle. Residents of Kazan - the capital of 
the Republic, the inhabitants of the medium-sized towns- Naberezhniye Chelny, Elabuga, Nizhnekamsk, Chistopol, Leninogorsk, Almetievsk, as well as of the rural areas - Laishevo, Kukmor, Arsk and Vysokaya Gora districts were questioned. The obtained data have been processed using the methods of mathematical statistics with the use of computer technologies. The investigation program consisted of theoretical and procedural parts divided into stages of the study. The first one contained the formulation and justification of the problem, definition of the object and subject of study, the purpose and objectives of the study, preliminary analysis of the system object of study, logical analysis of the basic concepts, the hypothesis. The organizational part included the procedures of determination of the total sample, the work plan, characteristics of the methods of collecting primary sociological information and the methods of computer processing of the primary information. Our questionnaire included 68 points concerning a vast scope of difficulties of ethnocultural development: the legal regulation of linguistic and cultural processes, the need for special measures for the development of national culture, language, verbal communication and behavior, the conditions under which inter-ethnic relations, the interaction of cultures will be optimal, the importance of the confessional factor in consolidation of ethnic groups. Here we represent some of the results obtained from the research according to the questionnaire items.

Table 1. The existence of demand for the admission to your own national culture

\begin{tabular}{cccccc}
\hline & Answers & Frequency & Percent & Valid percent & Cumulative percent \\
\hline \multirow{4}{*}{ Valid } & Yes & 526 & 58.4 & 59.4 & 59.4 \\
& No & 233 & 25.4 & 26.3 & 40.6 \\
\multirow{4}{*}{ Missing } & Difficult to answer & 126 & 14 & 14.2 & \\
& Total & 885 & 98.3 & 100 & 100 \\
& No answer & 15 & 0.16 & & \\
& Total & 900 & 100 & & \\
\hline
\end{tabular}

Table 2. Satisfaction in general to join the national culture and language in the Republic of Tatarstan

\begin{tabular}{cccccc}
\hline & Answers & Frequency & Percent & Valid percent & Cumulative percent \\
\hline \multirow{4}{*}{ Valid } & Yes & 483 & 53.6 & 53.7 & 53.7 \\
\multirow{4}{*}{ Missing } & No & 249 & 27.6 & 27.7 & 46.3 \\
& Difficult to answer & 166 & 18.4 & 18.4 & \\
& Total & 898 & 99.7 & 100 & 100 \\
& No answer & 2 & & & \\
& Total & 900 & & & \\
\hline
\end{tabular}

Table 3. Attention to the development of national cultures, esthetic, moral, political, organizational, entrepreneurial culture of the population in the Republic of Tatarstan

\begin{tabular}{cccccc}
\hline & Answers & Frequency & Percent & Valid percent & Cumulative percent \\
\hline \multirow{4}{*}{ Valid } & Yes & 452 & 50.2 & 51.8 & 51.8 \\
\multirow{4}{*}{ Missing } & No & 326 & 36.2 & 37.3 & 48.2 \\
& Difficult to answer & 94 & 10.4 & 10.9 & \\
& Total & 872 & 9.6 & 100 & 100 \\
& No answer & 28 & 3.2 & & \\
& Total & 900 & 100 & & \\
\hline
\end{tabular}

\section{Discussion on the Research Outcomes}

The analysis of the works on the problem considered in the article has shown that the scientific researches on the problem of inter-cultural communications in a multi-ethnic regional social field, taking into account their influence on the inter-ethnic relations in a multi-lingual regional social field, are conducted widely and systematically, embracing the linguistic, lingvo-sociological, sociological, psychological, ethnographical and cultural studies.

Everyday practice of inter-cultural interactions, which are diverse and many-sided, supported by deep-rooted ageold traditions of cooperation, exchange and mutual enrichment of the national cultures of the peoples living on the territory of the Republic of Tatarstan serves as a guarantee of the lasting, strong and stable inter-ethnic concord based on the principles of tolerance, consensus and mutual respect of the language differences and cultural peculiarities of the ethnic communities of the Republic. 
The conceptualization and generalization of the data of concrete sociological investigations on the problems of inter-cultural interactions and their influence on the character of inter-ethnic relations in the multi-lingual space of the Republic of modern Tatarstan has allowed to making some important conclusions touching upon a number of aspects and sides of the problem of interrelations of inter-cultural cooperation and consolidation of the ethnic groups taking part in the cooperation, which form the population of the Republic. Of these conclusions we shall specially point out the following:

the majority of the representatives of the ethnic communities of the Republic have formed for themselves a stable need for a housel to the national culture, which fact can be characterized as a necessary condition for a similar stable interest in future to the culture of the neighboring peoples;

over one half of the population of Tatarstan irrespective of the national identity attach decisive significance to such a factor of inter-cultural cooperation and ethnical consolidation of the population of the Republic as "presence or absence in the regional community of national, religious or other conflicts";

- over a half of the questioned people use the Russian language as the main language of communication with representatives of their own nationality "at work" and "in public places" which can evidently be explained by the influence of the age-old tradition, when the Russian language dominated in these spheres both in prerevolutionary Russia and in the Soviet Union; the mentioned fact is more likely to encourage the inter-cultural cooperation and inter-ethnic consolidation, for any effective interaction of cultures in a multi-lingual space is possible only with the existence of at least one language understood by everybody, or at least by the majority of the people acting in such a space;

in spite of the importance of bilingualism declared by most respondents, only about half of the questioned people have a command of both State languages of the Republic of Tatarstan today, and the overwhelming majority of them are Tatars; such a situation can hardly be called an optimal condition for the development of inter-cultural cooperation on bi- and multi-lingual basis with the use of two or more languages;

it is hard to overestimate the significance of the preferences of the respondents found in the process of questioning for the development of inter-cultural communications as a condition for consolidation of ethnic groups, preferences that touch upon personal characteristics, that a modern person ought to have; among them are such as "readiness for pluralism of opinions", "tolerance", "tolerance for other people's opinion"; it is those characteristics that are needed for more constructive, all-sided and deep inter-cultural cooperation, interethnic unity and concordance.

\section{Conclusion}

The aspect of the global problem of inter-cultural and inter-ethnic communications in a multi-lingual social space has an imperishable actuality, like the problem on the whole. The analysis of the interaction of cultures and the process of consolidation made on a regional level within the framework of the multi-ethnic community of Tatarstan has shown that the mentioned social interconnection has many dimensions, and therefore must be studied as a complex, with the use of linguistic, sociolinguistic, sociological, cultural studies and other disciplinary means of cognition - theoretical elaborations, methodologies and methods. In other words, the most productive method of its investigation, understanding and explanation is an inter-disciplinary approach. The analysis of the regional particularity of the influence of inter-cultural communications on the consolidation of ethnicity in a multilingual space has revealed many complexities and contradictions in the system of interaction "inter-cultural communication - consolidation of ethnic groups in a multi-lingual medium", that has formed and is functioning in the Republic of Tatarstan. Consequently, research work in this field must be conducted being oriented for practical application of their achievements. The conclusions drawn in the article will be taken into account for the evolvement in practical programs of optimization of inter-cultural interactions with a prospect of their stronger, deeper and many-sided influence on the consolidation of inter-ethnic peace and concord in the multiethnic and multilingual space of the Republic.

\section{Acknowledgment}

The work is performed according to the Russian Government Program of Competitive Growth of Kazan Federal University. 


\section{References}

Berezina, L.G. (2011). Language politics as a factor of development of the spiritual potential (regional aspect). Bulletin of the economy, law and sociology, 1, 178-183.

Davletshina, D.M. (2012). Indicative - cluster analysis of the quality of the cultural potential of young people in the multiethnic environment of modern Russia (sociological aspect). PhD thesis. Saratov: Saratov State University.

Durkheim, E. (1893). On division of Public Labor. [Electronic Resource]. http://www.rbyoga.ru

Epstein, M. (1996). The phoenix of philosophy. On the meaning and significance of contemporary Russian thought. A Journal of Russian Thought, 1, 35-74.

Gabdrakhmanova, G.F. (2013). Turko-Tatar vector of Russian ethnology: the 25th anniversary of the Department of Ethnology Institute of History of the Academy of Sciences of the Republic of Tatarstan. Ethnographic Review, 5, 162-178.

Gilmanov, A.Z., \& Mavlyautdinov, J. (2010). Islam in Tatarstan: the practice of inter-religious peace and the consolidation of society. Naberezhnye Chelny: Kama State. Engineering - Economic Academy.

Graczeva, G. (2015). Tatarstan territoriya edinstva. [Electronic Resource]. http://www.protatarstan.ru/thems/tatarstan_territoriya_ edinstva

Hofstede G. (1990). The presentation of self in everyday life. Penguin Books.

Iskhakova, Z.A. (2001). Bilingualism of Tatarstan's cities (1980-90s). Kazan: KFU.

Kozhanov, A.A. (2009). Karelian national movement. Part 1. From Congress to Congress: Collection of materials and documents. Petrozavodsk: Karelian Scientific Centre of Russian Academy of Sciences.

Le Petit Larousse (1995). Illustré 1996 en couleurs-Dictionnaire encyclopédique.

Lipatova, T.N. (2012). Value preference, and spiritual potential of the population in the context of ethnic and cultural development of the region (on materials of the Republic of Tatarstan). PhD thesis. Kazan: Kazan (Volga) Federal University.

Makarova, G.I. (2012). Ethnic identity and the Russian Republic of Tatarstan in the context of changes in the ethno-cultural policy. PhD thesis. Saransk: Mordovia State University.

Ostroumov, A.I., \& Ostroumova, O.F. (2013). Creativity and creative learning as component of modernization of Russian education. Historical, Philosophical, Political and Juridical Sciences, Culturology and Art History: Questions of Theory and Practice, 2 (28), 149-153.

Schtompka, P. (1996). Sociology of social change. Moscow: Aspect Press.

Valeyeva, A.F. (2004). Linguistic behavior in the polyethnic society (theory and methodology aspects). Social processes and institutes in the transforming society. Moscow: The University and the school.

Vasilyeva, V.N. (2013). Interrelation of linguistics, dialectics and phycology in formation of communicative competence of foreign language students. In: V.N. Vasilyeva (ed.) Actual Questions of the Role of Romanic Languages and Modern Methods of Their Teaching. Kazan: KFU.

Zamaletdinov, R.R., \& Sibgayeva, F.R. (2013). National and cultural concepts. Kazan: KFU. 